\title{
Deafhood: um conceito em formação no campo dos Estudos Surdos no Brasil
}

\author{
Deafhood: a concept in formation in the field of Deaf Studies in Brazil \\ Deafhood: un concepto en formación en el campo de los Estudios Sordos en \\ Brasil
}

\section{Sueli de Fátima Fernandes}

Professora doutora na Universidade Federal do Paraná, Curitiba, Paraná, Brasil. suelif@globo.com

ORCID - https://orcid.org/0000-0003-1349-7004

\section{Francisco Martins Lopes Terceiro}

Mestre pela Universidade Federal do Paraná, Curitiba, Paraná, Brasil. terceiro.libras@gmail.com

ORCID - https://orcid.org/0000-0001-5909-6092

Recebido em 6 de junho de 2019

Aprovado em 17 de julho de 2019

Publicado em 22 de outubro de 2019

\section{RESUMO}

Os Estudos Surdos em Educação são um recente campo de pesquisa que tem como objeto o estudo da diferença linguística e cultural das comunidades surdas, pela problematização da histórica narrativa colonialista lançada aos surdos a partir de uma suposta normalidade ouvinte. O conceito de Deafhood, cunhado pelo pesquisador e ativista britânico surdo Paddy Ladd, recobre inúmeras contribuições ao campo ao problematizar o sistema de representações dominantes sobre identidade(s), diferença, alteridade, relações de poder e os efeitos de tais questionamentos nos processos educativos. Por meio de pesquisa bibliográfica, são selecionadas nove publicações de Paddy Ladd, a partir de 1998, não traduzidas no Brasil, com o objetivo de apresentar uma discussão sobre o conceito de Deafhood e sua potencialidade para o debate dos direitos linguísticos e culturais dos surdos. Deafhood revela-se uma ferramenta conceitual "guarda-chuva" que tem como núcleo as relações de poder envolvendo surdos e ouvintes. A produtividade dessa categoria conceitual é evidenciada pela sua ampla apropriação nas publicações de reconhecidos intelectuais surdos e ouvintes brasileiros. A centralidade dada à denúncia do audismo como expressão do colonialismo ouvinte recobre importantes reflexões na construção de uma epistemologia surda, centrada na produção de pesquisadores surdos subalternos e nas dinâmicas e multifacetadas produções culturais das comunidades surdas. As publicações selecionadas para estudo trazem contribuições originais aos modos de interrogar discursos e práticas colonialistas hegemônicas, operando nos deslocamentos discursivos que mobilizam o campo dos Estudos Surdos e fortalecendo a luta política por garantia de direitos linguísticos aos surdos no contexto nacional.

Palavras-chave: Deafhood; Comunidade surda; Direitos linguísticos. 
http://dx.doi.org/10.5902/1984686X38455

\section{ABSTRACT}

Deaf Studies within the Education is a recent research field whose object is the study of linguistic and cultural differences of Deaf communities, by problematising the historic colonial narrative imposed on the Deaf from a supposed hearing normality. The concept of Deafhood, defined by Paddy Ladd, preeminent British researcher and activist, covers multiple contributions to the field by problematising the dominant representation systems about identity(ies), difference, alterity, power relations and the effects of such approach in educational processes. The bibliographical research methodology used nine Paddy Ladd works, not yet published in Brazil, with the aim of proposing a discussion about the concept of Deafhood and its potential contribution to the linguistic and cultural rights of the Deaf. Deafhood proves itself to be a powerful overarching conceptual tool anchored at the power relations among hearing and Deaf peoples, capable to inform both the political and academic spheres. It is widely adopted in the studies of acclaimed Deaf and hearing Brazilian intellectuals. Its centrality of the denouncement of audiology as an expression of hearing colonialism brings about important reflections to inform a Deaf epistemology that is centered in the production of subaltern Deaf researchers and on the dynamic and multifaceted cultural productions of the Deaf communities. The works by Paddy Ladd used in this research offer original contributions to the framing of inquiries the hegemonic colonialist discourses and practices by acting on the displacement of the discourses that mobilize the field of Deaf Studies and by strengthening the political mobilisation to guarantee linguistic rights for the Deaf in the national context.

Keywords: Deafhood; Deaf community; Language rights.

\section{RESUMEN}

Los Estudios Sordos en Educación son un reciente campo de investigación que tiene como eje central el estudio de la diferencia lingüística y cultural de las comunidades sordas, por la problematización de la narrativa historica colonialista lanzada a los sordos a la mirada de una supuesta normalidad oyente. El concepto de Deafhood, creado por el investigador y activista británico sordo Paddy Ladd, abarca innumerables contribuciones al campo, al problematizar el sistema de representaciones dominantes sobre identidad(es), diferencia, alteridad, relaciones de poder y los efectos de tales cuestionamientos en los procesos educativos. Por medio de la investigación bibliográfica se seleccionan nueve publicaciones de Paddy Ladd, a partir de 1998 , no traducidas en Brasil, con el enfoque de presentar una discusión sobre el concepto de Deafhood y su potencialidad para el debate de los derechos lingüísticos y culturales de los sordos. Deafhood se muestra una herramienta conceptual como un "paraguas" que tiene como estructura central las relaciones de poder abarcando sordos y oyentes. La productividad de esta categoría conceptual es evidenciada por su amplia apropiación en las publicaciones de reconocidos intelectuales sordos y oyentes brasileños. La centralidad añadida a la denuncia del audismo como expresión del colonialismo oyente cubre importantes reflexiones en la construcción de una epistemología sorda centrada en la producción de investigadores sordos subalternos y en las dinámicas y multifacetadas producciones culturales de las comunidades sordas. Las publicaciones seleccionadas para este estudio aportan contribuciones originales a los modos de interrogar discursos y prácticas colonialistas hegemónicas, actuando en los desplazamientos discursivos que movilizan el campo de los Estudios Sordos y fortaleciendo la lucha política por garantía de derechos lingüísticos a los sordos en el contexto nacional.

Palabras clave: Deafhood; Comunidad surda; Derechos linguísticos. 
http://dx.doi.org/10.5902/1984686X38455

\section{Introdução}

Certa desordem, que se pretende revolucionária, abala o cenário político e acadêmico nacional, a partir dos anos 1990, orquestrada por novas e instigantes vozes de pesquisadores internacionais vinculados ao campo dos Estudos Surdos (ou Deaf Studies), até então, desconhecidas no Brasil. Wortmann, Vorraber Costa e Hessel Silveira (2015) explicam que os Estudos Surdos compõem uma área de produção de conhecimento que se constitui como desdobramento dos Estudos Culturais em Educação, campo que busca inverter a histórica narrativa colonialista lançada a grupos políticos minoritários como negros/as, mulheres, LGBTQs, pessoas com deficiência, surdos, entre outros, problematizando o sistema de representações dominantes sobre identidade, diferença, alteridade, relações de poder e os efeitos de tais questionamentos nos processos educativos.

Com destaque à produtividade da cultura, os Estudos Culturais buscam ressignificar discursos relacionados ao campo pedagógico. A ressignificação busca cambiar modos de olhar o Outro, colocando sob suspeita, todas as formas de fixar, essencializar e/ou naturalizar sistemas representacionais (conceitos, saberes, artefatos, práticas pedagógicas): "ela implica estranhar, desfamiliarizar ou tornar explícito o que estava naturalizado, deslocando e ampliando, nesse processo, significados e seus efeitos produtivos" (WORTMANN; VORRABER COSTA; HESSEL SILVEIRA, 2015, p. 35).

No Brasil, dos anos 2000, a educação de surdos se encontrava ainda fortemente marcadas por concepções e práticas de normalização, calcadas no modelo clínicoterapêutico da surdez (SKLIAR, 1998) que tem como principal objetivo a oralização das crianças e jovens surdos, por meio de programas, metodologias e técnicas de reabilitação oral e auditiva, com apoio de tecnologias da audição, como próteses e o implante coclear. Essa representação do campo pedagógico naturalizado como um domínio clínico é objeto de questionamento e ressignificação pelos Estudos Surdos.

Seria justo dizer que o abalo provocado pelos Estudos Surdos na academia foi respaldado pela mobilização do movimento surdo nacional, que organiza uma agenda política de universalização de direitos (humanos e linguísticos) que passam pela defesa e reconhecimento da língua brasileira de sinais (Libras) e por relações de poder mais assimétricas entre surdos e ouvintes. Esse movimento político protagonizado por ativistas surdos alimenta-se, mutuamente, das pesquisas em Estudos Surdos que emergem nas 
http://dx.doi.org/10.5902/1984686X38455

universidades, inspirados nos pressupostos dos Estudos Culturais e nos modelos culturais da surdez.

Rapidamente, um amplo feixe temático de pesquisas que inauguraram uma virada epistemológica nos modos de conhecer, explicar e narrar a surdez e as experiências surdas passa a ser conhecido e consumido nacionalmente. Citamos as mais representativas pelo fato terem sido efetivamente incorporadas às políticas educacionais nacionais/locais para surdos, como é o caso de investigações sobre a cultura surda (SKLIAR,1998; STROBEL, 2008; PERLIN e MIRANDA, 2003; KARNOPP; KLEIN e LAZZARIN, 2011), a identidade surda (PERLIN, 1998); a língua de sinais brasileira (QUADROS E KARNOPP, 2004) a literatura surda (SILVEIRA, KARNOPP e ROSA, 2003, 2005; KARNOPP, 2006); os movimentos surdos (THOMA e KLEIN, 2010) e o letramento bilíngue para surdos (FERNANDES, 2003; 2008).

Esse breve cenário introdutório tem a intenção de emoldurar o contexto em que se situa a personagem que motiva a produção deste artigo: o ativista e pesquisador surdo britânico Paddy Ladd. Muitas das pautas da agenda política dos surdos e das temáticas de pesquisa dos Estudos Surdos, a que nos referimos, são desdobramentos das reflexões sobre as comunidades surdas e sua cultura, sistematizadas em um trabalho seminal de Paddy Ladd, sua tese "In Search of Deafhood: Towards na Understanding of British Deaf Culture", defendida em dezembro de 1998, que lhe conferiu o grau de Doutor em Filosofia, na University of Bristol (Faculty of Social Science/Department of Deaf Studies - UK).

O título da tese "Em busca da Deafhood: em direção a um entendimento da Cultura Surda Britânica" [tradução nossa] já nos desafia a interpretação desse neologismo cunhado pelo autor - Deafhood - categoria conceitual por meio da qual Paddy Ladd desenvolve, ao longo de oito capítulos, instigantes e inovadoras discussões acerca da língua, da cultura, das práticas e relações sociais da comunidade surda britânica, desafiando o leitor a converter o olhar afeito às narrativas médicas dos surdos como "deficientes da audição".

Temos como objetivo apresentar uma discussão sobre o conceito de Deafhood e sua potencialidade para o debate dos direitos linguísticos e culturais dos surdos. Sob a forma de um ensaio teórico, utilizamo-nos da pesquisa bibliográfica como procedimento metodológico, realizando o levantamento das publicações de Paddy Ladd, não traduzidas no Brasil, a partir de 1998. De um conjunto obras do autor, selecionamos aquelas em que 
http://dx.doi.org/10.5902/1984686X38455

as reflexões sobre Deafhood nos revelam a polissemia que essa categoria conceitual encerra.

\title{
Paddy Ladd e sua trajetória
}

\begin{abstract}
Reconstituir uma história feita de lacunas, de interstícios e silêncios não é tarefa fácil. Quando as fontes escritas são reticentes, é sempre preciso buscar informação no entre dito, juntar fragmentos dispersos: é a "necessidade de lidar com silêncios", surpreendendo o ainda não formulado (SÜSSEKIND; DIAS; AZEVEDO, 2003, p. 108).
\end{abstract}

A epígrafe inicial sintetiza nosso percurso na busca por conhecer Paddy Ladd e sua história, fragmentada em blogs e sites dispersos, matérias de jornais e vídeos na internet com pouquíssimas informações e fatos consistentes sobre sua vida pessoal, que nos permitisse construir um perfil coeso e coerente da sua biografia.As fontes alternativas e publicações, não acadêmicas, como vídeos com palestras, entrevistas e autorrelatos (em British Sign Language - BSL) vão contribuindo na composição da imagem de uma personalidade heterodoxa, curiosa e extremamente original, esse incrível pesquisador surdo que foi ativista do movimento hippie dos anos 1970, na Inglaterra.

Paddy Ladd nasceu em 1952, no Reino Unido e, como milhares de outros surdos, viveu durante vinte e dois anos sem conhecer a língua de sinais de seu país - British Sign Language (BSL) - o que aconteceu somente após sua formação no ensino superior, como assistente social, no ano de 1973. Sobre esse período que viveu sem contato com a comunidade surda, ele narra a experiência da oralização que marcou a sua infância e adolescência e, como a maioria de seus pares, o colocou na situação de apenas mais um "deficiente" na sociedade.

A conexão com sua identidade surda ocorre quando Ladd, aos 22 anos, conhece a BSL na experiência real do contato surdo-surdo, pois, até então, seu conhecimento sobre a vida comunitária dos surdos era teórico e referenciado na leitura de textos sobre o tema. A grande mudança se dá no momento em que Ladd acessa o "mundo dos Surdos" e ele descreve como "[...] aquilo foi minha incursão na comunidade surda, o caminho da minha vida, estando em casa, onde eu pertenço [...]" (LADD, 2006, não paginado).

Além da aprendizagem tardia da língua de sinais, outros fatos marcaram a trajetória de Ladd, sendo, o mais significativo, a sua atuação como assistente social de crianças e jovens surdos e seus familiares. Nesse convívio foi batizado culturalmente na comunidade surda com o sinal de "Jesus", na língua de sinais britânica (BSL), justificado pela 
http://dx.doi.org/10.5902/1984686X38455

semelhança de sua imagem de cabelos longos e barba à figura de Cristo. Na primeira foto da figura 1, Paddy Ladd está sinalizando Deafhood e, nas demais imagens está representado o seu sinal "Jesus" em BSL e escrita de sinais:

Figura 1 - Paddy Ladd e Deafhood.

\begin{tabular}{|c|c|c|}
\hline $\begin{array}{c}\text { Paddy Ladd e o Sinal } \\
\text { Deafhood(BSL) }\end{array}$ & SINAL - "JESUS" em BSL & $\begin{array}{c}\text { SINAL - "JESUS" em } \\
\text { SIGNWRITING } \\
\text { (Escrita de sinais) }\end{array}$ \\
\hline
\end{tabular}

Fonte: Terceiro (2018, p. 36).

Essa experiência de identificação cultural vivenciada pelo aprendizado da BSL para ele foi singular, pois Ladd pode perceber a forte influência negativa do oralismo sobre sua vida e de seus pares surdos, proibidos de usar a língua da comunidade. Desde então, não mediu esforços para mudar esse contexto para as novas gerações surdas, somando forças com outras pessoas que pensavam como ele para criar a NUD (National Union of Deaf). A União Nacional dos Surdos (NUD) foi fundada em Wimbledon, Londres, em 13 de março de 1976, com a intenção de fortalecer um instrumento de atuação política exclusivamente administrado pelos próprios surdos. A NUD reuniu os primeiros grupos de surdos operários, no século $X X$, com objetivo de reivindicar direitos linguísticos e sociais, negados no último século pela escola oralista.

A NUD buscava um trabalho de conscientização de direitos sociais e tornou-se um grupo de pressão, envolvendo vários surdos em campanhas e eventos voltados à tomada de decisões que afetavam sua vida social, principalmente nas escolas, pelo fato de a língua de sinais não ser o meio de acesso à informação e comunicação prioritário. Era um período de pouco acesso dos surdos às escolas e a NUD fazia críticas a esse processo de exclusão, questionando os métodos educacionais adotados, como também criticando organizações e associações de surdos formadas por grupos de surdos "elitizados", que obtinham relativo sucesso nos programas de oralização. Apesar de ter sido um momento importante e poderoso na organização de trabalhadores, com mudança das concepções em relação aos 
http://dx.doi.org/10.5902/1984686X38455

surdos, a NUD (e Paddy Ladd) fez muitos inimigos pelas duras críticas sociais que trazia sobre a falta de políticas sociais para surdos. Ladd destaca a importância da NUD para o fortalecimento dos Surdos como movimento social e sua inserção no campo das lutas póscoloniais:

\begin{abstract}
Um movimento subalterno surdo o primeiro grupo de pressão visto no Reino Unido, a União Nacional dos Surdos (NUD), foi formada em 1976. Ao contrário do BDA, a corrida por uma combinação de missionários ouvintes e surdos da elite, o NUD foi fundamentalmente um movimento subalterno formado por ativistas familiarizados com os avanços "pós-coloniais" e Consciência Negra da década de 1960. Seu sucesso não só trouxe à tona a questão da apropriação do controle das pessoas ouvintes sobre os problemas dos surdos, mas problematizou a aptidão dos líderes surdos que tinham conhecimento para operar sob tais sistemas (NUD, 1977) (LADD, 1998, p.35) [Tradução livre dos autores].
\end{abstract}

A difusão midiática das bandeiras de luta dos surdos também foi uma empreitada de Paddy Ladd, que trabalhou na rede de televisão britânica BBC, na década de 1980, como o primeiro apresentador surdo de TV, no programa "See Hear", uma revista semanal de variedades sobre temas que afetavam à comunidade surda; inaugurou as primeiras experiências de tradução de canções sinalizadas em shows de astros como Bob Dylan e Grateful Dead, demonstrando o potencial simbólico e cultural da língua de sinais nas artes. Essas diversificadas intervenções sociais levaram-no a receber uma importante homenagem em reconhecimento a sua atuação política e de investigação na área dos Estudos Surdos, no XV Congresso Mundial de Surdos, promovido pela World Federation of the Deaf, em 2001.

Obviamente, Ladd percebeu que a academia seria um importante espaço de disputa para difundir a nova visão das pessoas surdas como integrantes de uma minoria linguística e cultural, em detrimento da visão de "deficientes" que sempre as estigmatizou. Sua incursão como pesquisadora surdo e, posteriormente, como professor da Universidade de Bristol, credenciou-o a propor a criação do primeiro curso de mestrado em cultura surda. $\mathrm{O}$ programa do curso refletiu a trajetória investigativa de Paddy Ladd durante o curso de doutorado, cuja tese apresentou como objetivos:

[i] entender a relevância cultural de agrupamentos sociais dentro da comunidade surda britânica; [ii] averiguar diferenças que uma mudança histórica pode fazer na conceitualização da cultura; [iii] compreender o papel de disposições e estratégias individuais dentro da cultura e estar ciente de quaisquer variáveis significativas que possam exigir atenção (LADD, 1998, p. 9) [Tradução livre dos autores]. 
http://dx.doi.org/10.5902/1984686X38455

Seu percurso acadêmico para legitimar a definição de uma cultura surda britânica foi inspirado em militância política, nas contribuições teóricas do campo dos Estudos Culturais e na Etnografia Crítica como abordagem metodológica. Sua tese foi um trabalho de grande fôlego teórico, em que ele dialoga com a Antropologia Crítica, os Estudos Culturais e outras teorias pós-coloniais, projetando o futuro do panorama de pesquisas na área, pela proposição de uma profusão de temas desdobrados da categoria "cultura surda", cujas raízes e multiplicidade investigou nas experiências das escolas residenciais para surdos (modelo educacional predominante à época), nos clubes e associações em que ele caracteriza as diferenças de classe média surda e dos operários surdos, de modo a caracterizar um modelo de cultura surda com uma dimensão nacional no Reino Unido.

A leitura do trabalho e a riqueza das reflexões que ele enleva não apenas afirma a existência e o valor da cultura surda, mas traz importantes interrogações sobre as comunidades surdas nacionais e suas potenciais contribuições a um projeto educacional de descolonização dos surdos, até então, sob a direção de especialistas ouvintes das áreas médicas e terapêuticas.

A tese transformou-se em livros, capítulos de livros e outras publicações de grande circulação, contribuindo para o debate da insurgente epistemologia surda de base linguístico-cultural. Infelizmente, sua produção é veiculada predominantemente em inglês, uma barreira linguística que impede o acesso a esses textos pela imensa maioria dos surdos brasileiros, cujo direito a um processo de letramento, mesmo na língua nacional - o português - ainda não se concretiza nas escolas de educação básica.

Justifica-se, assim, a importância da pesquisa de mestrado que originou este artigo, desenvolvida também por um pesquisador "subalterno" surdo que buscou superar o desafio das fronteiras linguísticas (Libras, Português, Inglês) que perpassaram o estudo das obras, como primeiro passo para tornar acessível a epistemologia surda proposta nos escritos de Paddy Ladd a outros pares surdos e ouvintes brasileiros.

\section{Deafhood: um conceito em investigação}

Deafhood é um conceito que estende seus tentáculos por muitos domínios e interpretações. A pesquisa bibliográfica realizada partiu de um conjunto de dez textos, todos em língua estrangeira (inglês predominantemente e espanhol), escritos por Ladd ou em coautoria. Neste artigo, dedicamo-nos a apresentar Deafhood como ferramenta conceitual, 
http://dx.doi.org/10.5902/1984686X38455

cotejando reflexões presentes em algumas dessas publicações (LADD,1998, 2002, 2003, 2005a, 2005b; 2013a; 2013b; WOLL \& LADD, 2003; LADD \& GONÇALVES, 2011) com destaque ao texto seminal de sua tese de doutorado "In Search of Deafhood: Towards na Understanding of British Deaf Culture (LADD, 1998).

O livro "Em busca da Surdidade I: Colonização dos Surdos", publicado em Portugal, em 2014, é a única obra traduzida em português lusitano, não disponível para venda no Brasil, que organiza uma compilação resumida de temas abordados na tese de Paddy Ladd sobre Deafhood e seus domínios políticos e epistemológicos. Além do livro lusitano, tivemos acesso a uma única publicação em português, sob a forma de capítulo de livro, "Culturas Surdas e o desenvolvimento de Pedagogias Surdas" (LADD \& GONÇALVES, 2011),que Ladd assina em coautoria com Janie Gonçalves, pesquisadora ouvinte e filha de pais surdos, sua primeira orientanda brasileira, com tese de doutorado defendida na Universidade de Bristol, em 2009.

A pesquisa de Paddy Ladd inaugura um amplo e multifacetado campo teórico investigativo que se propõe dar protagonismo à mentalidade surda (Deaf Way) e sua história de resistência, contemplando uma gama significativa de categorias conceituais que buscam edificar o que ele caracteriza como uma epistemologia surda. Observamos que as reflexões e análises de Paddy Ladd, nessa tarefa, são construídas pelo esforço de buscar imagens do cotidiano para situar e acomodar os complexos raciocínios que ele desenvolve ao processamento da cultura visual e da língua de sinais dos surdos.

llustramos uma delas, presente no capítulo inicial de "Em busca da Surdidade I Colonização dos Surdos" (LADD, 2013), em que o pesquisador "desenha" com palavras uma metáfora que toca o coração das pessoas surdas, na seção "Inside the Museum Deafness Goes on Trial' (Dentro do museu a surdez vai a julgamento), pedindo aos seus leitores o esforço do pensamento visual: que se coloquem em frente a um prédio em cuja entrada, pendurado por cima da porta, há um letreiro onde se lê "SURDEZ".

Entramos no prédio com ele e nos deparamos com uma sala onde estão cuidadosamente dispostos por todos os cantos e paredes, objetos ligados ao processo de colonização a que foram submetidos os surdos, durante o século que ele caracteriza como de opressão oralista: aparelhos de surdez de todas as épocas, modelos e tamanhos, imagens em quadros representando um futuro no qual a manipulação genética, altamente evoluída, seria capaz de recriar a audição e extirpar a surdez; quadros de ilustres 
http://dx.doi.org/10.5902/1984686X38455

personagens que escreveram a história de oralização dos surdos, grandes especialistas que "desmutizaram" surdos nobres, experiências com indivíduos surdos realizadas por audiologistas, médicos e pedagogos a serviço do oralismo triunfante, que vigiu como método educacional dominante, desde sua legitimação no Congresso de Milão, realizado na Itália, em 1880.

Chama-nos, a certo ponto, a atenção para o fundo dessa sala, onde há uma parede, por detrás da qual os surdos e os seus aliados têm disputado com os curadores do museu outra epistemologia da surdez. Ladd nos dá a certeza de que atrás da parede existem artefatos culturais (objetos, pinturas, fotografias, esculturas, etc) que retratam uma outra narrativa, que se contrapõe ideologicamente àquela apresentada no acervo da "surdez", onde os corpos surdos são objetos a serem normalizados. A tarefa a que Ladd se propõe é abrir uma porta naquela parede, que nos permita entrar na sala, até então desconhecida e fechada, e nela explorar esses novos artefatos e sua simbologia, reorganizando sua mobília para recriar a narrativa histórica da surdez e dos surdos, por meio de uma leitura antropológica e cultural das suas vivências comunitárias. Um século de opressão linguística, diz ele, deixou poucas comunidades surdas aptas (ou predispostas) a apresentar a sua versão na tradição escrita. Daí a importância de que as histórias tão apaixonadamente transmitidas pelas figuras dos quadros e artefatos culturais possam ser "lidas" na nova porta, agora derrubada, que passará a ser a porta principal de entrada do museu, com a inscrição: "Cultura Surda e Deafhood" (LADD, 2013, p. 4).

A metáfora do museu nos introduz a pensar na primeira grande síntese epistemológica que Ladd se propõe a realizar, problematizando os valores e práticas que contrapõem ideologicamente os modelos clínico-terapêutico da surdez e o modelo linguístico-cultural. Sua argumentação percorre os estudos socioantropológicos para assemelhar a influência do modelo clínico-terapêutico na vida e educação de surdos a um processo de colonização, pela perspectiva do discurso da surdez (deafness). Constrói um raciocínio argumentativo sobre as práticas de colonização dos surdos pelos ouvintes que se utilizaram das mesmas estratégias de violência simbólica e institucional para destruir culturas minoritárias como a dos povos africanos, indígenas e outras minorias étnicas submetidas ao poder colonizador europeu, desde os séculos XV e XVI.

Em suas publicações, Ladd (1998, 2002, 2003, 2013; 2013) discute o colonialismo ouvinte por meio de reflexões trazidas pelo psicólogo estadunidense Harlan Lane, que 
http://dx.doi.org/10.5902/1984686X38455

registrou os primeiros estudos que analisavam, sob a forma de colonialismo, as práticas paternalistas desenvolvidas por familiares, médicos, psicólogos e outros especialistas preocupados com o tratamento e a cura da surdez.

Lane explica que o colonialismo pode ser caracterizado a partir da padronização de concepções e práticas sociais em que formas de opressão estão envolvidas: "a subjugação física de um povo enfraquecido, a imposição de uma língua e de costumes estrangeiros, e o controle da educação em nome dos objetivos do colonizador" (LANE, 1992, p. 43). Demonstra, com exemplos irrefutáveis, a narrativa de patologização da surdez presente na literatura da "Psicologia da Surdez" em que os surdos foram descritos como pessoas de pensamento concreto e limitado, imaturos e agressivos, com linguagem pobre e primitiva e moralmente desintegrados.

A educação oralista, a partir desse raciocínio, constituiu suas práticas de reabilitação oral e auditiva do indivíduo "anormal", negando a língua de sinais como uma possibilidade de humanização e denunciando o seu uso como prejudicial ao desenvolvimento social, cognitivo e afetivo das crianças e jovens surdos. A partir de sólidos argumentos científicos de pesquisas objetivas nas áreas da psicologia e saúde, que descrevem os surdos sinalizantes como seres privados da audição e da linguagem, com racionalidade incompleta, o oralismo buscou/busca extirpar comportamentos sociais desajustados e traços de personalidade e características emocionais inadequadas (visibilizadas pelo uso de gestos e língua de sinais na comunicação, por exemplo), a partir da imposição de um padrão etnocêntrico do ser "ouvinte" como norma (LADD e LANE, 2013).

O colonialismo sobre os surdos veste a "máscara da benevolência" (o título do livro de Lane) para disfarçar seu caráter perverso, assumindo o paternalismo para justificar as boas intenções da retidão das decisões dos benfeitores ouvintes. Na verdade, Lane explica que essa lógica alimenta interesses econômicos e pessoais de um grande "mercado de reabilitação" formado por médicos, audiologistas, terapeutas, educação especial, indústrias de aparelhos e tecnologias da audição, especialmente voltados aos "deficientes da audição e da linguagem", ao longo do século XX. Um mercado extremamente lucrativo operado e controlado por ouvintes que diz-se "voltado aos interesses e necessidades dos surdos". O paternalismo é, assim, definido como um "sistema segundo o qual uma autoridade empreende a satisfação das necessidades e a regulação da conduta daqueles que estão sob o seu controle" (LANE, 1992, p. 48). A autoridade se materializa em políticas sociais ativas 
http://dx.doi.org/10.5902/1984686X38455

com a intenção de erradicar ou marginalizar a língua de sinais e a cultura surda, como um mal a ser extirpado.

A relação que se estabeleceu, a partir dessa lógica paternalista e colonialista ouvinte, subjugou os surdos a uma relação de dependência dos ouvintes benfeitores, cujos valores e princípios passam a ser incorporados e interiorizados pelos próprios sujeitos "colonizados", que passam a reproduzir sua existência a partir dos padrões de normalidade, socialmente aceitos e valorizados. O sucesso da normalização do corpo surdo vale-se de um complexo processo intersubjetivo por meio do qual a assimilação da colonização ouvinte é naturalizada pelos próprios surdos que, incutidos dos valores e práticas sociais do colonizador, apropriamse das formas de ser e agir como "ouvintes", valorizando e defendendo os instrumentos utilizados em seu processo de colonização (a fala, os aparelhos auditivos, os implantes cocleares, a negação da língua de sinais...) para existir.

Nessa mesma linha argumentativa, Lane convoca as reflexões do educador e pesquisador surdo estadunidense Tom Humphries, que desenvolve o conceito de "audismo", para singularizar o colonialismo praticado contra os surdos:

[...] instituição corporativa para lidar com surdos, fazendo declarações sobre eles, orientando e aprovando opiniões sobre eles, descrevendo-os, dando lições sobre eles, orientando o local em que frequentam as aulas, e em muitos casos, onde moram; em suma, o audismo é a forma de dominação dos ouvintes, reestruturando e exercendo a autoridade sobre a comunidade surda (PADDEN \& HUMPHRIES, 1990 apud LANE, 1992, p. 52).

O audismo, em síntese, é a forma particular de colonialismo praticada sobre os surdos, e se institucionaliza nas famílias, nas escolas, nas terapias, nos modos da invenção da surdez como uma falta, desde meado dos séculos XIX e ao longo de todo o século XX.

Paddy Ladd se dispõe a percorrer uma jornada acadêmica e política para edificar uma contranarrativa de resistência surda anticolonialista, baseada na perspectiva cultural. A denúncia de Ladd à opressão etnocêntrica ouvintista reforça as perdas sofridas: o audismo retirou direitos e cerceou o florescimento e desenvolvimento das línguas de sinais como expressão cultural, invisibilizou histórias vivenciadas pelo povo surdo, retardando seu ingresso na jornada do Deafhood, para a (auto)compreensão da cultura surda.

O conceito de Deafhood é traduzido por "Surdidade", na edição lusitana do livro "Em busca da Surdidade I - Colonização dos Surdos", e apresentado no glossário como segue: 
http://dx.doi.org/10.5902/1984686X38455

Este termo foi desenvolvido em 1990 pelo presente autor, a fim de iniciar o processo de definição do estado existencial dos Surdos como 'ser-no-mundo'. Até agora, o termo médico 'surdez' foi usado para englobar essa experiência dentro da categoria mais ampla de 'deficiente auditivo', a grande maioria dos quais eram pessoas idosas 'com problemas de audição', de modo a tornar invisível a verdadeira natureza da existência coletiva surda. A Surdidade não é vista como um estado finito, mas como um processo através do qual os indivíduos Surdos chegam a efetivar sua identidade surda, postulando que aqueles indivíduos constroem aquela identidade em torno de vários conjuntos de prioridades e princípios ordenados de maneiras diferentes, que são afetados por diversos fatores, como nação, era e classe. (LADD, 2013, p. 1415) [grifo nosso]

Embora reconheçamos a importante contribuição da tradução de Deafhood para Surdidade no português lusitano, seguimos utilizando, neste manuscrito, o termo no original, em inglês, buscando ir revelando o conceito nos estudos originais do autor, da mesma forma como ele narra esse processo de ir ressignificando essa palavra e seus múltiplos sentidos, à medida que o tempo passava (LADD, 2005).

Como apresenta Ladd, Deafhood pode ser inicialmente entendido como uma ferramenta conceitual que possibilita pensar a descolonização do corpo surdo, por meio da tomada de consciência do longo processo histórico de colonização que muitas gerações de surdos viveram e da descoberta de uma nova identidade cultural e coletiva, centrada nas experiências das comunidades surdas. Os saberes do colonialismo ouvinte sedimentaram discursos em torno da "surdez" (deafness), que remete a uma condição fixa de sentido operada pelo uso do sufixo ness. Por isso o autor propõe, em seu lugar, um neologismo que busca o efeito de sentido de contraposição, pelo sufixo hood, usado em inglês para formar substantivos abstratos que descrevem uma condição de ser uma coisa particular, singular, como ele vê a experiência da coletividade surda, ao longo da história.

Deafhood, neste sentido, aponta para um estado do "ser", dinâmico, particular e transitório que Ladd justifica necessário para criar um novo território discursivo, uma nova linguagem, como primeiro passo para representações outras dos surdos, distanciadas da "surdez", e do audismo como expressão do colonialismo ouvinte. A criação de um novo "termo" para se contrapor à surdez é também, para ele, uma arma simbólica de combate e de resistência.

Caracterizamos Deafhood como um conceito guarda-chuva que tem como núcleo as relações de poder envolvendo surdos e ouvintes. Apontamos Deafhood como categoria conceitual política e teórica que tem sido apropriada em publicações de reconhecidos intelectuais surdos e ouvintes brasileiros, desde os anos 1990, operando deslocamentos 
http://dx.doi.org/10.5902/1984686X38455

discursivos na construção do campo dos Estudos Surdos e fortalecendo a luta política de ativistas surdos por garantia de direitos linguísticos, no contexto da educação bilíngue nacional.

Ao percorrermos as inúmeras obras em que Deafhood assumia a centralidade idealizamos a representação dessa ferramenta conceitual sob a imagem de um guarda-chuva que abriga inúmeras categorias em disputa como "leigo", "alienado", "surdez", "cultura surda", "comunidade surda", "modelo linguístico-cultural”, "modelo clínico-terapêutico", "(des)colonialismo", "subalterno surdo", "pesquisador subalterno surdo", "classe social”, entre outros, tal qual representamos na figura 4.

Figura 2 - Deafhood e seus desdobramentos

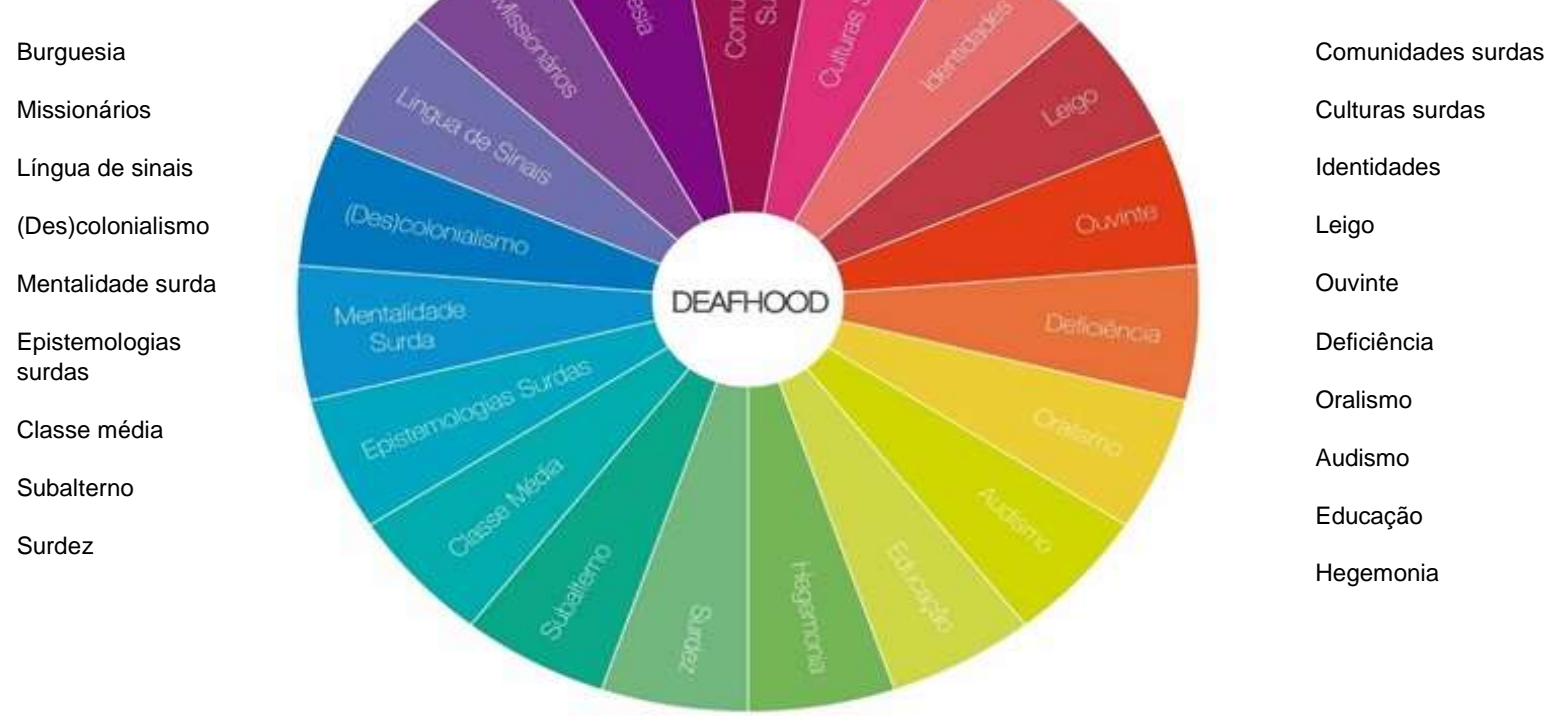

Fonte: Adaptado de Terceiro (2018, p. 50).

A imagem nos põe a refletir sobre Deafhood como um conceito que recobre relações de poder, julgamentos de valor contraditórios, variáveis de classe, de identidades, em um cenário de tensionamentos dinâmico, e nunca estático. Em síntese, se nos fosse permitido sugerir uma expressão (não uma tradução) para o sentido principal que Deafhood suscita, nossa proposta seria "existência surda". Uma existência surda coletiva, transhistórica, em movimento e transformação constante, a depender dos interesses, da correlação de forças, da maior ou menor capacidade de enfrentamento dos significados e sentidos atribuídos aos surdos e à surdez, em cada momento histórico. Uma existência materializada nas 
http://dx.doi.org/10.5902/1984686X38455

comunidades surdas que, embora marginalizadas por muitas décadas, não pereceram e resistiram.

Deafhood sintetiza as contraditórias experiências vivenciadas pelos surdos, ao longo de sua existência como grupo, marcadas por concepções e práticas que ora operam para fixar as forças centralizadoras da opressão e colonização, ora operam para a descentralização das forças da luta e da resistência. Deafhood se propõe a ser essa arena discursiva de disputas nos modos de representação do coletivo de pessoas surdas como integrantes de uma minoria linguística, que distância qualitativamente a vida cultural dos surdos, da narrativa da surdez como uma deficiência que acomete indivíduos. Não se trata, portanto, de um conceito fixo e monolítico, já que é uma ferramenta analítica para a expressão dos deslocamentos nas representações sociais dos surdos.

\section{Deafhood e as contribuições ao campo dos Estudos Surdos}

Paddy Ladd advoga que a descolonização deve ter como base a construção de uma epistemologia surda, definida como "maneiras surdas de estar no mundo, de conceber esse mundo e o seu lugar ali (tanto na realidade como potencialmente)" (LADD, 2013, p. 34-35), valorizando a importância das relações das pessoas surdas entre si e os seus modos de narrar essa experiência.

O modelo cultural e linguístico supõe que a experiência surda seja entendida não apenas como uma experiência cultural segregada, mas que suas lutas sejam aproximadas ao universo das opressões sofridas por outros grupos quase organizam politicamente pela descolonização e conquista de direitos sociais, como é o caso de mulheres, povos indígenas e negros, por exemplo. Isso exige dos não-surdos (ou ouvintes)uma mudança no olhar sobre a alteridade surda na perspectiva da diferença. O modelo cultural e linguístico não se presta apenas a refutar o termo "surdez" do campo da medicina, ele se propõe a capturar e estabelecer sistemas de valores transmitidos historicamente pelos povos surdos de sua singular experiência sobre o que significa ser humano, unicamente centrada em elementos visuais-gestuais-táteis (LADD, 2005a).

Apesar de todo o aparato audista para destruir a existência surda, houve resistência em relação à proibição de uso da própria língua durante o século oralista, mantendo-a viva nos encontros culturais em clubes e outras formas de agrupamento de surdos, ao redor do mundo. Milhares de crianças, jovens e adultos não-surdos estiveram envolvidos nessas 
http://dx.doi.org/10.5902/1984686X38455

experiências interculturais com gerações após gerações formadas por crianças surdas nascidas de pais surdos (Ladd julga que sejam 10\% dos membros das comunidades surdas), aprendendo e mantendo viva a língua de sinais como um potente artefato cultural e de comunicação na comunidade surda. Surdos de pais surdos operaram pela manutenção da cultura e da(s) identidade(s) surda(s) que se fortaleceram ao longo de gerações: "[...]e assim isto é Deafhood: alguém não apenas torna-se "surdo", mas mantém essa identidade "surda", diante de décadas de negações diárias" (LADD, 2005a, p. 14-15). O que significa identidade surda para cada grupo em cada uma das gerações surdas não tem um sentido fixo e estável, mas o conteúdo epistemológico ou ontológico da explicação de cada homem, mulher e criança sobre o que significa ser surdo e estar no mundo (para si e para o outro) é o que deve ser considerado como Deafhood.

Wool e Ladd (2003) explicam que o conceito de comunidade surda vem sendo estudado por diversos autores há 150 anos, apresentando três fatores para caracterizá-las: a surdez, a comunicação visual e o apoio mútuo. Esses três aspectos criam "comunidades de comunicação" (communities of communication), "comunidades de identidade étnica" (communities of ethnicidentity) e "comunidades de solidariedade" (communities of solidarity) (Johnsonn apud LADD, 2003). No sentido mais prático, o fato central da adesão à comunidade surda é determinado por um critério linguístico, pela forma de comunicação, ou seja, pelo uso ou não de uma língua sinalizada, o que eles denominam "surdez atitudinal" (atitudinal deafness), e não é determinada por medição audiológica (BAKER; COKELY,1980 apud LADD, 2003, p.3). Por representar um produto cultural a língua de sinais pode ser aprendida por todas as pessoas, democraticamente, que estarão conectadas a uma comunidade e a uma cultura pelo seu uso.

No entanto, Ladd adverte para as diferenças internas existentes nas comunidades surdas que podem criar a ilusão de novas epistemologias que, na verdade, são reproduções dos discursos audistas, ainda que proferidos por surdos. No curso do desenvolvimento de sua pesquisa de doutorado sobre a cultura surda britânica, frequentou clubes, associações, grupos políticos, identificando diferenças geracionais, linguísticas, culturais, de religião e de classe social, associadas a variáveis como raça, imigração e gênero que produziam diferentes visões sobre o ser/estar surdo em um mundo majoritariamente ouvinte.Essa riqueza de diversidade na experiência histórica na comunidade Surda, entretanto, tinha um elemento comum: todos foram colonizados pelas práticas oralistas em escolas residenciais, 
http://dx.doi.org/10.5902/1984686X38455

compartilhavam a BSL como primeira língua e narravam suas vivências de forma diversa. A imersão nesse universo permitiu a Ladd compreender o sentido coletivo da existência surda e propor a passagem de deafness (em torno das perspectivas audiológicas) para Deafhood (em torno de perspectivas culturais e linguísticas) (LADD, 1998, p.2).

Dessa experiência antropológica surge a necessidade de formalizar uma epistemologia surda, onde os conceitos de cultura e comunidade surda tivessem destaque e valorizassem o papel dos intelectuais surdos, suscitando reflexões em relação a conceitos como "pesquisador surdo subalterno", "leigo", "aliado", entre outras definições. O conceito que gostaríamos de destacar, pela recorrência na sua tese de doutorado, é "subaltern researcher" (pesquisador subalterno), que Ladd explica como a agência do próprio sujeito que viveu a condição subalterna (em relação ao colonialismo ouvinte) na produção de conhecimento sobre si e sua cultura. O conceito de "pesquisador subalterno" busca a virada epistemológica de mudanças na estrutura dos discursos fixados nos últimos séculos, sob a perspectiva do colonizador ouvinte que edificaram barreiras, impedindo a conquista do espaço e reconhecimento acadêmico pelos subalternos surdos. (LADD, 1998; 2002; 2003; 2013).

Importante destacar uma importante diferenciação em relação à posição de subalterno observada por Ladd que envolve a posição de poder e assimilação da cultura ouvinte pelos surdos.

Como já debatemos, a condição de Deafhood não se define apenas por graus de perda auditiva, mas resulta do cruzamento de indicadores de reconhecimento e prestígio, obtidos por níveis de escolarização e status de emprego, valorizados socialmente. Para Ladd esses valores estão intimamente atrelados ao fato de dominar a língua oral majoritária: ouvi-la, ainda que parcialmente, falar, ler e escrevê-la. Visto assim esses indicadores ajudam a criar diferenciações na comunidade surda entre aqueles surdos que podem partilhar dessas práticas - surdos oralizados, parcialmente surdos ou ensurdecidos e surdos letrados - em relação aos surdos que não o fazem. Estabelece-se, assim, a divisão entre "Deaf subaltern elites" e (elites surdas subalternas) e "Deaf subalterns" (surdos subalternos), essencialmente monolíngues em língua de sinais, trabalhadores operários que têm consciência de sua diferença de "classe". Paddy Ladd estava particularmente ocupado em fazer florescer o conhecimento deste último grupo de subalternos, 
http://dx.doi.org/10.5902/1984686X38455

oportunizando o registro de sua língua de sinais, de seus modos de interação, organização e produção de conhecimento.

O campo dos Estudos Surdos partilha essa premissa como um princípio de existência, incorporando as vozes dos surdos à academia, valorizando a autoimagem e sua representação política, para gerar novos discursos sobre si e dar visibilidade social aos seus artefatos culturais. A riqueza dos estudos produzidos pelos próprios olhos de pesquisadores e intelectuais surdos, revelam dores e opressões que não podem ser narradas senão pela "pele surda", como procuramos praticar na produção da dissertação que originou este artigo. A superação dos desafios da colonização passa, necessariamente, pela formação de pesquisadores e professores surdos como modelos na infância surda, fortalecendo laços de identificação linguística e cultural, já que a colonização é uma ameaça permanente para um grupo que se identifica politicamente minoritário na sociedade.

Nessa discussão, Ladd ressignifica um conceito importante para caracterizar a posição de ignorância de inúmeros pesquisadores em relação à cultura surda e suas práticas discursivas e sociais: "leigos". Leigo é o conceito que remete tanto a surdos e ouvintes que desconhecem aspectos culturais e comunitários dos surdos. O conhecimento científico produzido por especialistas da surdez/deficiência auditiva promove a naturalização de certo "ouvintocentrismo", quando distanciados das singularidades que constituem Deafhood: "a compreensão e consciência da ressignificação do conceito de leigo, nesses termos, [...] é central para eventual reviravolta dos padrões culturais opressivos que todos nós interiorizamos" (LADD, 2013, p. 21).

Difícil estabelecer um ponto final para esse debate, dadas as várias possibilidades e múltiplas perspectivas e sentidos que Deafhood nos apresenta para apreender a experiência coletiva de cultural dos surdos. Algumas delas foram já suficientemente debatidas no cenário nacional, por pesquisadores surdos subalternos, de forma pioneira, fortalecendo o campo dos Estudos Surdos em Educação.

Gladis Perlin, em sua tese de doutorado em educação "O Ser e o Estar Sendo Surdos: Alteridade, diferença e identidade", defendida em 2003, na linha de Estudos Culturais, da Universidade Federal de Rio Grande do Sul, sob orientação do Prof. Dr. Carlos Skliar, argumenta que Deafhood se derivou do conceito de identidade que Ladd, e também ela, buscavam no campo dos Estudos Culturais e que foi melhor desenvolvido quando Ladd adentrou nos estudos pós-estruturalistas, na sua produção tardia. Ela alega que não 
http://dx.doi.org/10.5902/1984686X38455

acompanhou essa fase posterior e aguardou a publicação do livro derivado da tese para conhecer o conceito em profundidade. Perlin traduz o conceito Deafhood como "Ser Surdo", ou seja, Deaf $=$ Surdo e hood $=$ Ser, expressão utilizada em sua tese de doutorado, que traz reflexões sobre as identidade(s) surda(s), a alteridade surda, a diferença e os Estudos Surdos. Segundo Perlin:

[...] o ímpeto de responder essas perguntas, o processo de tornar-se - estes eu chamei de Deafhood. Deafhood declara que o como nós temos sido nesses últimos 120 anos não é tudo o que somos de verdade [O conceito Deafhood] afirma que existe um senso surdo de ser, tanto dentro do indivíduo quanto no coletivo, tal qual um rio, que se propulsiona contra a barragem $e$ não pode descansar enquanto não encontra uma forma que o conduza ao mar da vida, onde todas as almas são capazes tanto de encontrar sua autoexpressão integral quanto se interpenetrarem. (LADD apud PERLIN, 2003, p. 110).

Certamente, a impossibilidade de aprofundamento do conceito, a partir do acesso às produções futuras de Ladd, podem ter causado limitações à interpretação de Deafhood, nas pesquisas de Perlin, já que, como o próprio autor descreve, o conceito se transforma, ao longo de suas investigações. Isso não interfere na originalidade do pensamento da autora, já que a interlocução teórica entre ambos foi dificultada, também porque eles estavam desenvolvendo pesquisas no mesmo tempo histórico do final da década de 1990. Sendo a primeira doutora surda a propor uma nova narrativa sobre os surdos e suas identidades, no Brasil, rompendo com uma tradição de normalização, Perlin abre os caminhos acadêmicos em um cenário ainda escasso de pesquisadores subalternos surdos emergentes. Nesse sentido, a pesquisadora surda subalterna traz uma relevante contribuição à estruturação dos Estudos Surdos em Educação, como reconhecida e legítimas referência para os surdos do Brasil que, depois, e também por causa dela, passaram a ocupar os espaços acadêmicos.

\section{Considerações finais e Deafhood continua...}

Neste ensaio teórico buscamos apresentar uma discussão sobre o conceito de Deafhood, cunhado pelo pesquisador e ativista britânico Surdo Paddy Ladd, e sua potencialidade para o debate dos direitos linguísticos e culturais dos surdos.Ladd cria 0 neologismo Deafhood em sua pesquisa de doutorado sem imaginar os desdobramentos e o valor dessa linguagem pioneira e original para a tomada de consciência e empoderamento dos pares surdos que se materializam, nas décadas seguintes, como um novo campo 
http://dx.doi.org/10.5902/1984686X38455

epistemológico: os Estudos Surdos (Deaf Studies) em Educação.Deafhood mobiliza não apenas uma dimensão acadêmica, mas atua como um motor para despertar consciência se produzir ativismo político, sob a forma de movimento em defesa do povo surdo e da reparação das dívidas históricas da colonização ouvintista (LADD, 2002; LADD \& LANE, 2013, p. 575).

As leituras que compuseram a pesquisa bibliográfica sobre o tema, nos permitiram apreender a amplitude de sentidos que circulam sob esse conceito "guarda-chuva", encarnado em um neologismo que faz circular uma nova linguagem para representar a história dinâmica das comunidades surdas, ao longo de séculos. Mais particularmente, no campo teórico dos Estudos Surdos, as reflexões de Paddy Ladd assumem significativa repercussão na produção brasileira por meio da ampla e rápida difusão de categorias teóricas como "cultura surda", "comunidade surda", "identidades surdas", "audismo", "modelo clínico-terapêutico" e "modelo linguístico-cultural (ou socioantropológico), desde a década de 1990.

Há uma gama de conceitos debatidos pelo autor, contudo, inexplorados no Brasil, como é o caso de "leigo(s)", "aliado(s)", "pesquisador subalterno", a questão da "classe média surda", o "Deaf Way", o "Deaf Power", e o "Deaf Gain" (sem proposta de tradução) entre outras tantas portas abertas pelo pesquisador surdo britânico que podem não ter repercutido nacionalmente, na academia, seja pela inexistência de traduções das publicações em língua portuguesa, seja pela dificuldade de acesso à leitura em língua estrangeira por subalternos surdos, interlocutores preferenciais do autor.

Não tivemos como intenção esgotar a discussão sobre essa polissêmica ferramenta conceitual que se apresenta cunhada na forma Deafhood. Nossa abordagem buscou contextualizar o surgimento do termo, a partir da perspectiva anticolonialista assumida por Paddy Ladd, com destaque às categorias "epistemologia surda" e "pesquisador surdo subalterno" para ilustrar reflexões teóricas utilizadas na análise e caracterização da cultura surda britânica em sua diversidade interna.

A centralidade dada à denúncia do colonialismo nas publicações selecionadas para estudo (LADD, 1998, 2002, 2003, 2013a, 2013b) nos trouxeram contribuições inovadoras e originais nos modos de retratar a histórica opressão ouvintista, hegemônica no último século, sobre as vidas surdas, as línguas de sinais, as comunidades surdas e suas produções culturais coletivas. 
http://dx.doi.org/10.5902/1984686X38455

Embora o processo de descolonização dos surdos ainda esteja "engatinhando" nas diferentes maneiras de reconhecer a existência surda, Deafhood nos oferece grande potencial para reflexão e produção de contranarrativas que se prestam à ruptura de discursos sobre a surdez com base em modelos médicos hegemônicos.

O fato de termos a coautoria de um investigador surdo subalterno, neste texto, demarca o nosso posicionamento político em relação a fazer circular essas vozes mantidas silenciadas e que agora registram, na academia, a perspectiva dos surdos sobre seus pares (sujeitos de um coletivo histórico), sobre si próprios e sobre o seu Outro (ouvinte), nas posições de opressor ou aliado nas lutas pela descolonização.

Aderimos à provocação de Paddy Ladd, quando narra a metáfora do museu, abrindo novas portas para divulgar narrativas silenciadas sobre a surdez e os surdos, como estratégia de luta e resistência política, na conquista de direitos linguísticos e sociais.

\section{Referências}

FERNANDES, Sueli de Fátima. Educação bilíngue para surdos: identidades, diferenças, contradições e mistérios. 2003. (Tese) Doutorado em Letras. Programa de Pós-Graduação em Letras. Curitiba-PR, Universidade Federal do Paraná, 2003.

FERNANDES, Sueli. Letramento na educação bilíngue para surdos: caminhos para a prática pedagógica. A língua portuguesa no mundo. São Paulo: FFLCH, p. 1-30, 2008.

KARNOPP, Lodenir Becker. Literatura surda. ETD: Educação Temática Digital, v. 7, n. 2, p. 98-109, 2006.

KARNOPP, Lodenir; KLEIN, Madalena; LAZZARIN, Márcia Lise Lunardi. Cultura surda na contemporaneidade: negociações, intercorrências e provocações. Ed. da ULBRA, 2011.

LADD, Paddy. In Search of Deafhood: Towards an understanding of British Deaf Culture. Tese. Doutorado em Filosofia. Faculdade de Ciências Sociais, Departamento de Estudos Surdos. Unigted Kingdom: Universidade de Bristol, 1998.

LADD, Paddy. Colonialism and Resistence: A Brief History of Deafhood, p. 42-59, Open Your Eyes - Deaf Studies Talking. H-Dirksen L. Bauman (org.). Editora University of Minnesota Press, 2002.

LADD, Paddy. Understanding Deaf Culture - In Search of Deafhood. Multilingual Matters Ltd. 2003

LADD, Paddy. Deafhood: A concept stressing possibilities, not deficits. Scandinavian Journal of Public Health, p.12-17, 2005a. Disponivel em http://journals.sagepub.com/doi/abs/10.1080/14034950510033318. Acesso em 05/2016. 
LADD, Paddy. Golpes contra el imperio": Culturas sordas y educación de sordos. In: Conferencia presentada en el Vigésimo Congreso Internacional sobre Educación del Sordo (I. CE. D), Maastricht, Holanda. 19 de julio de 2005b. Disponível em: http://www.cultura-sorda.org/golpes-contra-el-imperio-culturas-sordas-yeducacion-desordos. Acesso em 12 de junho de 2017.

LADD, Paddy. About the author - Dr. Paddy Ladd. @ Paddy Ladd, 2006. Disponível em: http://www.deafhood.com/test/author.html. Acesso: 10 mar.2019

LADD, Paddy. Em Busca da Surdidade I. Colonização dos Surdos. Trad. Mariani Martini. Lisboa: Surd"Universo, 2013.

LADD, Paddy; LANE, Harlan. Deaf ethnicity, Deafhood, and their relationship. Sign Language Studies, v. 13, n. 4, p. 565-579, 2013.

LADD, Paddy; GONÇALVES, Janie. Culturas Surdas e o desenvolvimento de Pedagogias Surdas, p.295-330.in: Cultura Surda na contemporaneidade: negociações, intercorrências e provocações. KARNOPP, Lodenir Becker, KLEIN, Madalena; LUNARDI-LAZZARIN, Márcia Lise. Editora ULBRA, 2011.

LANE, Harlan. A máscara da benevolência: a comunidade surda amordaçada. Instituto Piaget. Lisboa, Portugal, 1992.

NATIONAL UNION OF DEAF (NUD). Blueprint for the Future. London: National Union of the Deaf, 1997.

PADDEN, Carol A.; HUMPHRIES, Tom. Deaf in América. Harvard University Press, 1990.

PERLIN, Gladis. Identidades surdas. In, SKLIAR, Carlos. A surdez: um olhar sobre as diferenças. Porto Alegre: Mediação, v. 1, p. 51-73, 1998.

PERLIN, Gladis Teresinha Taschetto; MIRANDA, Wilson. Surdos: o narrar e a política. Ponto de Vista: revista de educação e processos inclusivos, n. 5, p. 217-226, 2003.

PERLIN, Gladis. O ser e o estar sendo surdos: alteridade, diferença e identidade. (Tese de Doutorado em Educação da Linha Estudos Culturais), Universidade Federal de Rio Grande do Sul, 2003. Porto Alegre - RS.

QUADROS, Ronice Müller de; KARNOPP, Lodenir. Língua de sinais brasileira. Porto Alegre: Artmed, 2004.

SILVEIRA, Carolina Hessel; KARNOPP, Lodenir; ROSA, Fabiano Souto. Rapunzel surda. Editora da ULBRA, 2005.

SILVEIRA, Carolina Hessel; ROSA, Fabiano; KARNOPP, Lodenir. Cinderela surda. Canoas: Ed. ULBRA, 2003. 
http://dx.doi.org/10.5902/1984686X38455

SKLIAR, Carlos. A surdez: um olhar sobre as diferenças. Porto Alegre: Mediação, v. 3, 1998.

STROBEL, Karin. As imagens do outro sobre a cultura surda. Florianópolis: Editora da UFSC, 2008.

SÜSSEKIND, Flora; DIAS, Tânia; AZEVEDO, Carlito (Ed.). Vozes femininas: gêneros, mediações e práticas da escrita. 7Letras, 2003.

THOMA, Adriana da Silva; KLEIN, Madalena. Experiências educacionais, movimentos e lutas surdas como condições de possibilidade para uma educação de surdos no Brasil. Cadernos de Educação, n. 36, 2010.

WOLL, Bencie; LADD, Paddy. Deaf communities. Oxford handbook of deaf studies, language, and education, p. 151-163, 2003.

WORTMANN, Maria Lúcia; VORRABER COSTA, Marisa; HESSEL SILVEIRA, Rosa. Sobre a emergência e a expansão dos Estudos Culturais em educação no Brasil. Educação, v. 38, n. 1, 2015.

\section{Correspondência}

Sueli de Fátima Fernandes - Universidade Federal do Paraná, Departamento de Teoria e Fundamentos da Educação, Pça. Santos Andrade, 50 - subsolo. Curitiba, Paraná - Brasil. CEP: 81531900.

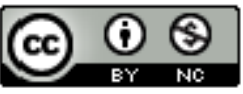

This work is licensed under a Creative Commons Attribution-NonCommercial 4.0 International (CC BY-NC 4.0) 